\title{
Surgery-Induced Changes in Erythrocyte and Plasma Lipid Peroxidation, Enzymatic and Non-Enzymatic Antioxidants of Female Rats: Protective Role of Heparin and Pentoxifylline
}

\author{
Halil Simsek' , Ali Said Durmus², Hamit Yildiz² \& Mehtap Ozcelik³
}

\begin{abstract}
Background: Intra abdominal adhesions are a complication that occurs after many abdominal surgical procedures, especially gynecological operations. These complications occur by irritating the peritoneum due to such circumstances as infection or surgical trauma, and are considered a pathological part of the healing process of peritoneal injury. It manifests itself with symptoms such as pain, intestinal or urethral obstruction and abdominal abscesses. Oxidative stress due to adhesions plays an important role on adhesion formation. In addition to many researches done at the point of prevention of adhesion and decreasing stress parameters, in this study, it was planned to determine the effect of Heparin $(\mathrm{H})$ and Pentoxifylline (PTX) on malondialdehyde (MDA) and some antioxidant values.

Materials, Methods \& Results: This study was performed on rats and thirty-seven female Sprague-Dawley rats were randomized into four groups. The first group was sham (Sh) group $(\mathrm{n}=7)$ and laparotomy was performed and $2 \mathrm{~mL}$ of $0.9 \%$ $\mathrm{NaCl}$ was applied. For all other rats $(\mathrm{n}=30)$ the small intestine was withdrawn and the uterus was uncovered and the anti mesenteric surfaces of the left uterine horn and left abdominal wall were superficially tilted until slight bleeding was seen. Lesion areas have been covered. Two $\mathrm{mL} 0.9 \% \mathrm{NaCl}$ to control (C) group $(\mathrm{n}=10), 500$ IU heparin to group $\mathrm{H}$, and 25 $\mathrm{mg} / \mathrm{kg}$ Pentoxifylline to group PTX $(\mathrm{n}=10)$ have been given and then the abdominal incision was closed. The adhesion score of group Sh was found to be more important than C and PTX groups $(P<0.05)$. The adhesion score of group $\mathrm{C}$ was determined to be more significant than group $\mathrm{H}(P<0.05)$. In group Sh, erythrocyte reduced glutathione $(\mathrm{GSH})$ levels were found to be more significant $(P<0.01)$ than $\mathrm{C}, \mathrm{H}$ and PTX groups whereas it was found that group $\mathrm{C}$ was more significant than group $\mathrm{H}(P<0.01)$. In group Sh, glutathione peroxidase $(\mathrm{GSH}-\mathrm{Px})$ activity was found to be more significant $(P<$ $0.05)$ than H and PTX groups, while MDA level was found to be lower and more significant $(P<0.01)$ than group C. In addition, group $\mathrm{C}$ was found to be higher and more significant $(P<0.01)$ than group H. Plasma vitamin E levels in Sh, $\mathrm{H}$ and PTX groups were found to be higher and more significant $(P<0.01)$ than group C. It is also observed that MDA levels in group $\mathrm{C}$ are higher and more significant $(P<0.01)$ than all groups. Nitric oxide $(\mathrm{NO})$ level in Sh group was found to be lower and more significant $(P<0.05)$ than the other groups whereas it is determined that $\mathrm{NO}$ level in $\mathrm{H}$ group is higher and more significant $(P<0.05)$ than group $C$. Activites of erythrocyte catalase $(\mathrm{CAT})$ and superoxide dismutase (SOD), the levels of plasma vitamin $\mathrm{A}$ and $\beta$-carotene were not important in all groups.

Discussion: Intra abdominal adhesions that occur due to operations performed in the abdominal region still remain as a major problem. This adhesion brings certain problems with itself. Various applications have been made to reduce these problems. In this study, it was observed that inhibition of heparin and pentoxifylline adhesions contributed to the reduction of MDA levels and the reduction of oxidative damage due to the increase in levels of Vitamin E, GSH, GSH-Px and NO levels. In conclusion, it is suggested that heparin and pentoxifylline should be used to prevent adhesions due to abdominal operations and to reduce oxidative damage.
\end{abstract}

Keywords: rat, heparin, pentoxifylline, adhesion, antioxidants, MDA. 


\section{INTRODUCTION}

Peritoneal adhesions are a frequently encountered problem. They are a consequence of incision, suturing, mechanical trauma, tissue ischemia, thermal injury, foreign materials and peritonitis of infectious origin [23]. Numerous mediators of inflammation such as arachidonic acid, cytokines, nitric oxide and oxygen-derived free radicals may participate in postoperative formation of adhesions [22]. It has been suggested that synthesis of reactive oxygen species (ROS) increases during surgery and is associated with formation of postoperative adhesions [22]. In the body, formed ROS are eliminated by enzymatic and nonenzymatic antioxidants [51]. Uncontrolled increase of ROS, however, can stimulate chain reactions by interacting with proteins, lipids and nucleic acids, causing cellular dysfunction and even death. In such a situation, administration of antioxidants should therefore give potential benefit by neutralizing ROS [51,54].

Heparin has been used as a prophylactic and therapeutic anticoagulant for many years. The most likely explanation for the mechanism of action of heparin is that it acts as an anticoagulant and activates antithrombin III, resulting in a reduction of fibrin clots $[13,41,49]$. It is also possible that the fibrin matrix is imperfect secondary to the heparin effect, making it more susceptible to the plasminogen activated into plasmin. Indeed, heparin directly stimulates the plasminogen activator activity and increases the plasmin action, which would enhance fibrinolysis [41,49]. It also probably stimulates macrophages to secrete the plasminogen activator $[13,14]$.

Pentoxifylline (PTX) is a synthetic methylxanthine derivate commonly used in the treatment of peripheral vascular diseases $[15,31,36,48]$. PTX has a vasodilatory effect and improves microcirculatory blood supply, decreases platelet aggregation, neutrophil infiltration, increases thrombolytic, thus avoiding small-vessel obstruction, improves the erythrocyte deformability and reduces the blood viscosity [36]. Furthermore, few animal studies have reported the capacities of PTX in preventing postoperative intraperitoneal adhesions $[31,45,48]$.

In this study, we investigated the effect of heparin and pentoxifylline on adhesion formation models.

\section{MATERIALS AND METHODS}

\section{Animals}

The study used 37 female Sprague-Dawley rats (4.5 month-old, weighing between 200 and 220 g) housed in a climate-controlled animal care facility (relative humidity of 40-60\% and temperature between 21 and $24^{\circ} \mathrm{C}$ ), with a $12 \mathrm{~h}$ light/dark cycle. The animals were provided with standard rat chow and water, ad libitum.

\section{Anesthesia and surgical procedure}

The rats were anesthetized with intramuscular ketamine $\left(\operatorname{Ketalar}^{\circledR}\right)^{1}$ at $85 \mathrm{mg} / \mathrm{kg}$ body weight and xylazine $\left(\operatorname{Rompun}^{\circledR}\right)^{2}$ at $6 \mathrm{mg} / \mathrm{kg}$ body weight. Following anesthesia, laparotomy was performed with a $3 \mathrm{~cm}$ midline incision. In the first, second and third groups of rats, the small bowel was retracted and the uterus was exposed. Punctate serosal hemorrhages were generated by scraping with a scalpel blade at the anterior wall and antimesenteric surface of the left uterine horn to create adhesions.

\section{Study groups}

The rats were divided into four groups. The first group was kept as the sham group (group Sh, $\mathrm{n}=$ 7), subjecting only to laparotomy and receiving $0.9 \%$ $\mathrm{NaCl}$ solution $(2 \mathrm{~mL})$ intraperitoneally. For all other rats $(n=30)$, the small bowel was retracted and the uterus was exposed. The anti-mesenteric surfaces of the left uterine horn and of the left abdominal wall were superficially scraped until slight haemorrhages have appeared on their surfaces. The lesion areas were coated and $2 \mathrm{~mL}$ of $0.9 \% \mathrm{NaCl}$ solution, of $500 \mathrm{IU}$ heparin $\left(\text { Nevparin }{ }^{\circledR}\right)^{3}$ or of Pentoxifylline (Trental ampul $\left.{ }^{\circledast}\right)^{4}$ were instilled in the peritoneal cavity of animals from the groups $\mathrm{C}, \mathrm{H}$ and PTX, respectively ( $n=10$ in each group). The abdominal incision was subsequently closed, the peritoneal and muscular layers with absorbable materials and the skin with 4/0 silk sutures. The animals were allowed to resume their diet until the 14th postoperative day. Rats in all groups were reanesthetized and laparatomy was performed. The abdominal cavity was inspected through a $U$ shaped incision of the anterior abdominal wall, which was retracted caudalad, providing maximal exposure. The adhesions were counted and graded by two independent investigators, who were blinded to the assigned groups, with the classification described by Nair et al. [35] (Table 1). 
H. Simsek, A.S. Durmus, H. Yildiz \& M. Ozcelik. 2018. Surgery-Induced Changes in Erythrocyte and Plasma Lipid Peroxidation, Enzymatic and Non-Enzymatic Antioxidants of Female Rats:.. Acta Scientiae Veterinariae. 46: 1619.

Table 1. Grading of postoperative adhesions.

\begin{tabular}{cr}
\hline Grade & Grading of adhesion \\
\hline 0 & Complete absence of adhesions \\
1 & Two bands, either between viscera or from viscera to the abdominal wall \\
2 & More than two bands between viscera or from viscera to the abdominal wall \\
3 & Multiple dense adhesions, or viscera directly adherent to the abdominal wall and extent of adhesive bands \\
4 &
\end{tabular}

Blood collection and preparation of blood samples

Just before the termination of the study, a blood sample (4-6 mL) was taken from the heart with a sterile injector with added EDTA, and placed into tubes, protected against light. Then bloods were separated into plasma and red blood cells (RBC) by centrifugation at $1800 \times g$ for $10 \mathrm{~min}$. Hemolyzed RBC and plasma samples were stored at $-30^{\circ} \mathrm{C}$.

\section{Oxidatif stress parameters}

Lipid peroxidation levels in plasma and hemolyzed RBC were measured with the thiobarbituricacid reaction by the method of Placer et al. [38]. The methods of Goth [24] were used for the determination of catalase (CAT) activities in hemolyzed RBC. The glutathione (GSH) content in RBC was measured at $412 \mathrm{~nm}$ on the spectrophotometer using the method of Sedlak and Lindsay [42]. Glutathione peroxidase (GPx) activity in $\mathrm{RBC}$ was measured at $37^{\circ} \mathrm{C}$ and $412 \mathrm{~nm}$ according to Lawrence and Burk [32]. Total superoxide dismutase (SOD) activity was determined according to the method of Sun et al. [46]. The protein content in the plasma and hemolyzed RBC was measured by method of Lowyr et al. [34] with bovine serum albumin as the standard. Vitamins A and E were determined in frozen plasma samples by a modification of the method described by Desia [18]. The levels of $\beta$-carotene in plasma samples were determined according to the method of Suzuki and Katoh [47]. The nitric oxide content of the plasma was determined by spectrophotometer (Schimadzu UV-1208) ${ }^{5}$ according to the method of Cortas and Wakid [16].

\section{Stastistical analysis}

Adhesion score data were analyzed using the Kruskal-Wallis test, whereas biochemical and hematological data were analyzed using one-way analysis of variance (ANOVA). The Duncan test was performed for multiple comparisons using the (SPSS 11.0) ${ }^{6}$. The data were expressed as means \pm standard errors (SEM). Results were considered statistically significant at $P<0.05$.

\section{RESULTS}

In the rats, adhesions were found between the deperitonealized antimesenteric surface of the left uterine horn and adjacent abdominal walls (Figure $1 \mathrm{a}-\mathrm{c}$ ). The average adhesion scores were $0.28 \pm 0.18,1.90 \pm 0.37$, $0.50 \pm 0.30$ and $1.10 \pm 0.23$ in groups Sh, C, H and PTX, respectively. The adhesion scores of the Sh group was significantly lower than that of $\mathrm{C}$ and PTX groups $(P<$ 0.05). The adhesion scores of the $C$ group was significantly higher than that of $\mathrm{H}$ group $(P<0.05)$ [Table 2].

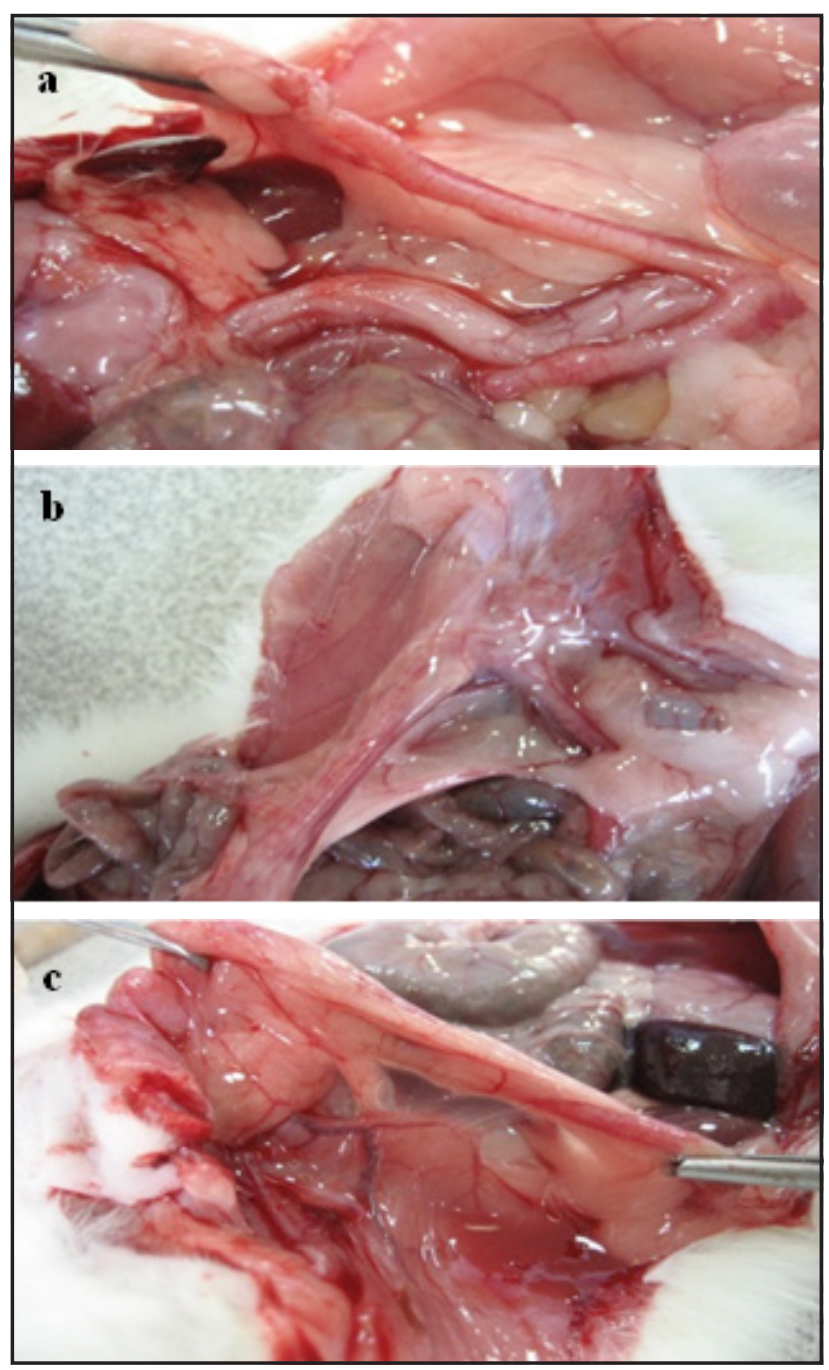

Figure 1. a- Level-4 peritoneal adhesion, a rat from control group. bLevel-0 peritoneal adhesion, a rat from Heparin group. c- Level-1 peritoneal adhesion, a rat from Pentoxifylline group. 
Table 2. Adhesion grading of the groups.

\begin{tabular}{ccccccc}
\hline \multirow{2}{*}{ Group } & \multicolumn{7}{c}{ Grade } & \multirow{2}{*}{ Average* } \\
\cline { 2 - 6 } & 0 & 1 & 2 & 3 & 4 & $0.28 \pm 0.18^{\mathrm{a}}$ \\
Sh $(\mathrm{n}=7)$ & 5 & 2 & - & - & - & $1.90 \pm 0.37^{\mathrm{b}}$ \\
$\mathrm{C}(\mathrm{n}=10)$ & 1 & 3 & 3 & 2 & 1 & $0.50 \pm 0.30^{\mathrm{ac}}$ \\
H $(\mathrm{n}=10)$ & 7 & 2 & - & 1 & - & $1.1 \pm 0.23^{\mathrm{bc}}$ \\
PTX $(\mathrm{n}=10)$ & 2 & 5 & 3 & - & - & . \\
\hline
\end{tabular}

abcWithin rows, means with different superscript letters differ significantly $(P<0.05)$. $*$ The data were expressed as means \pm standart errors (SEM).

Treatment with PTX significantly increased RBC GSH-Px $(P<0.05)$ and plasma VE $(P<0.01)$ levels (Tables 3-4). The RBC GSH $(P<0.01)$ levels and and plasma NO levels $(P<0.05)$, in the $\mathrm{H}$ group were significantly higher than in the $\mathrm{C}$ group. However, the levels of RBC and plasma MDA in group $\mathrm{H}(P<0.01)$ were lower than $\mathrm{C}$ group and plasma NO $(P<0.05)$ was significantly higher than group C. Plasma vitamin E levels in the PTX group were lower $(P<0.01)$ than in the $\mathrm{H}$ group. RBC GSH $(P$ $<0.01)$ levels and RBC and plasma MDA $(P<0.01)$ and plasma NO $(P<0.05)$ levels, in the Sh group were significantly lower than the $\mathrm{C}$ group. Plasma vitamin $\mathrm{E}(P<0.01)$ levels in the Sh group were significantly higher than the $\mathrm{C}$ group. Activites of erythrocyte catalase (CAT) and superoxide dismutase (SOD), the levels of plasma vitamin $\mathrm{A}$ and $\beta$-carotene were not important in all groups.

Table 3. RBC MDA and GSH levels and SOD, CAT and GSH-Px activity in the all groups (mean \pm SE).

\begin{tabular}{ccccc}
\hline Parameter & Sh $(\mathrm{n}=7)$ & $\mathrm{C}(\mathrm{n}=10)$ & $\mathrm{H}(\mathrm{n}=10)$ & $\mathrm{PTX}(\mathrm{n}=10)$ \\
\hline CAT $(\mathrm{k} / \mathrm{gr} \mathrm{Hb})$ & $129.31 \pm 9.94$ & $124.08 \pm 8.87$ & $148.27 \pm 16.21$ & $142.80 \pm 10.99$ \\
GSH $(\mu \mathrm{mol} / \mathrm{mL})$ & $0.82 \pm 0.01^{\mathrm{a}}$ & $0.98 \pm 0.03^{\mathrm{b}}$ & $1.08 \pm 0.02$ & $1.04 \pm 0.02$ \\
GSH-Px $(\mathrm{U} / \mathrm{gr}$ protein $)$ & $88.19 \pm 4.33^{\mathrm{c}}$ & $98.66 \pm 6.38$ & $103.13 \pm 5.49$ & $106.97 \pm 6.83$ \\
MDA $(\mathrm{nmol} / \mathrm{mL})$ & $10.86 \pm 0.28^{\mathrm{d}}$ & $11.80 \pm 0.29^{\mathrm{e}}$ & $9.69 \pm 0.40$ & $10.28 \pm 0.34$ \\
SOD $(\mathrm{U} / \mathrm{gr} \mathrm{Hb})$ & $1108.97 \pm 76.00$ & $1087.42 \pm 81.99$ & $1097.90 \pm 130.48$ & $1081.23 \pm 130.86$ \\
\hline
\end{tabular}

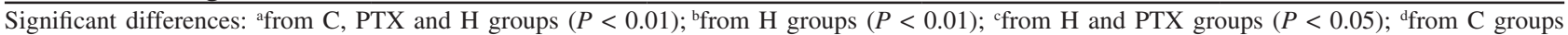
$(P<0.01)$ and ${ }^{\mathrm{e}}$ from $\mathrm{H}$ groups $(P<0.01)$.

Table 4. Plasma vitamin A, E, $\beta$-carotene, MDA concentrations and NO activity in the all groups (mean \pm SE).

\begin{tabular}{ccccc}
\hline Parameter & $\mathrm{Sh}(\mathrm{n}=7)$ & $\mathrm{C}(\mathrm{n}=10)$ & $\mathrm{H}(\mathrm{n}=10)$ & PTX $(\mathrm{n}=10)$ \\
\hline A Vitamin $(\mu \mathrm{mol} / \mathrm{L})$ & $0.94 \pm 0.10$ & $0.67 \pm 0.08$ & $0.79 \pm 0.15$ & $0.65 \pm 0.05$ \\
E vitamin $(\mathrm{mmol} / \mathrm{L})$ & $6.40 \pm 1.20^{\mathrm{dc}}$ & $5.25 \pm 0.32^{\mathrm{a}}$ & $7.58 \pm 0.30^{\mathrm{c}}$ & $6.28 \pm 0.35^{\mathrm{b}}$ \\
B-carotene $(\mu \mathrm{mol} / \mathrm{L})$ & $1.54 \pm 0.45$ & $0.99 \pm 0.10$ & $1.02 \pm 0.09$ & $1.16 \pm 0.21$ \\
MDA $(\mathrm{nmol} / \mathrm{mL})$ & $1.38 \pm 0.04^{\mathrm{ac}}$ & $1.51 \pm 0.01^{\mathrm{b}}$ & $1.36 \pm 0.03^{\mathrm{a}}$ & $1.44 \pm 0.03^{\mathrm{ab}}$ \\
$\mathrm{NO}(\mu \mathrm{mol} / \mathrm{L})$ & $30.13 \pm 0.58^{\mathrm{g}}$ & $31.01 \pm 0.08^{\mathrm{f}}$ & $31.41 \pm 0.11^{\mathrm{e}}$ & $31.26 \pm 0.05^{\mathrm{fe}}$ \\
\hline
\end{tabular}

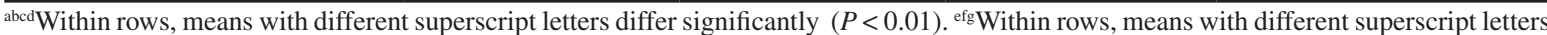
differ significantly $(P<0.05)$.

\section{DISCUSSION}

Despite all the struggles, organ adhesions after the abdominal surgery continue as an important problem today [37]. These adhesions often increase the risk of complications such as bowel obstruction, ileus, chronic abdominal pain, infertility, and certain systemic infections [19]. Heparin is an effective anticoagulant and it is indicated that with the application of local peritoneal instillation [21] and low-molecular weight heparin [4] healing can be observed without adhesion. It is stated that pentoxifylline inhibits adhesion formation by inhibiting phagocytosis in vitro and in vivo, the production of toxic oxygen products and proteolytic enzymes resulting from granulocytes [55].

There are many experimental models for constituting peritoneal adhesions [14,31]. As the uterine horn model mimics abdominal surgery $[14,45]$, the anti-mesenteric surfaces of the left uterine horn and of the left abdominal wall were scrapped until petechial spots appeared for developing intra-abdominal adhesions. Different classifications were proposed for grad- 
ing peritoneal adhesions $[3,13,35,48]$; among them, the NAIR model scoring adhesions from 0 to 4 according to their severity [35] was retained in the present study because of its simplicity.

When a fibrin matrix between serosa tissue surfaces is insufficiently developed, the adhesion formation is prevented [48]. The effect of heparin on adhesion formation may be accounted by its actions on platelet aggregation and macrophage functions leading to enhanced fibrinolysis after antithrombin III and plasmin activation $[13,14]$. It was previously demonstrated that heparin has a local action on the deperitonealized surfaces and directly accelerates fibrinolysis process [14]. In the present study, the intraperitoneal heparin adminis- tration has markedly reduced the adhesion formation in the rat uterine horns compared to the not treated controls.

On the other hand, pentoxifylline improves the tissue oxygenation and endothelial function and inhibits pro-inflammatory cytokine production, chemotaxis, platelet aggregation, tumour necrosis factor production by macrophages and neutrophil degranulation [36]. In the uterine horn model in rats $[31,48]$ and in rabbits [45], it was previously reported that PTX is able to reduce the adhesion formation after a primary injury. In another study, it was found that intraperitoneal pentoxifylline application significantly reduced adhesion formation compared to the control group [26]. In this study, the adhesion formation was slightly decreased in animals treated with PTX. Following surgery, the number of macrophages increases and switch in the cell functions is observed [33].

It has been reported that free oxygen radicals have important effects in adhesion formation after surgery [1,2]. Some investigations have been carried out to investigate free radical inhibitors such as SOD and CAT in the prevention of adhesion formation by antioxidant supplementation [3,44]. It is observed that antioxidant application reduced the severity and degree of adhesions after intestinal ischemia in rats [1]. Thus, it has been reported that heparin can act as a synergistic endogenous antioxidant with other free radical inhibitors $[25,41]$. PTX is a potent free radical scavenger and has a reducing effect on superoxide release and neutrophil degranulation [29].

Arslan et al. [7] found that blood MDA levels were higher in the adhesion group than in the control group. In another study, it was observed that in the comparison of the GSH level between the normal group and adhesion group, the decrease in the adhesion group was found to be at a significant level whereas the MDA level was found to be higher and more important in the adhesion group compared to the normal group [40]. In another study, the difference in MDA level between the control group and sham groups was found to be significant [6]. In a study by Atilgan et al. [10] MDA levels were found to be higher and more important in the adhesion group than in the control group. In a study carried out by Azine et al. [12], it is found that the difference in tissue MDA levels between sham and control groups was statistically significant. When comparing the control group with the pentoxifylline group, it was observed that the MDA level difference was significant. In the study by Askari et al. [9], the decrease in the control group was found to be significant when the tissue GSH level was compared with the control group, whereas the MDA level was found to be significant in the control group. In this study, erythrocyte and plasma MDA levels were found to be more important in the control group compared to heparin and sham group. It is observed that this result $[7,9,10,12,40]$ is consistent with the notifications of the researchers. The increase in MDA in the control group is caused by cleavage of lipid-containing structures such as plasma and cell membranes of oxygen radicals by the cells involved in the inflammatory response during the adventitious process [28,43].

GSH level was found to be more important in the control group compared to heparin and sham group. It was seen that the results were similar to the findings of [7,9]. GSH plays a central physiological role in protecting against endogenous and exogenous oxidants, toxic substances, DNA damaging agents and carcinogens, and maintaining body haemostasis and thus it clears oxygen radicals in the environment by maintaining intracellular GSH synthesis [20,39]. In addition, the difference between heparin and PTX groups of GSH and GSH-Px was not statistically significant in all groups of erythrocytes CAT and SOD. It was observed that GSH-Px activity was significantly reduced in the sham group compared to PTX and heparin groups. It has been reported here that GSX-PX increase in heparin and PTX groups shows that heparin can act as synergistic endogenous antioxidants with other free radical inhibitors [25,41]. Pentoxifylline is a powerful free radical scavenger and has a reducing 
effect on superoxide release and neutrophil degranulation [29]. Due to this situation, it is considered that the level in both groups is higher than the sham group. The increased activity of erythrocyte CAT and SOD may not be statistically significant because of the increase in free radicals due to exhaustion or inhibition $[5,30]$.

In study, the decrease of plasma $E$ vitamin in control group was statistically significant compared to sham, PTX and heparin groups. Vitamin E has protective effects on free oxygen radicals of cell membranes, collagen synthesis and platelet aggregation-reducing effects $[8,27,52,53]$. Vitamin E also inhibits the synthesis of thromboxane and prostaglandin with its inhibition effect on arachidonic acid metabolism, in which free oxygen radicals are so effective. Inhibition of thromboxane, a potent thrombocyte-aggre- gating factor, reduces the amount of fibroblasts by inhibiting thrombus formation and prevents adhesion formation by inhibiting fibrin formation [11,27,52]. Because of this effect, it is thought that the reason for the decrease of vitamin $\mathrm{E}$ in the control group compared to the other groups is due to the usage during the occurence of this effect.

In a study, NO levels were found to be higher and more important in the adhesion group than in the normal group [40]. In another study, it was observed that the NO level difference between the control group and sham groups was significant [6]. In the study conducted by Askari et al. [9], it was determined that the increase in the control group was significant when the tissue NO level was compared with the normal group and control group. In this study, the NO level difference was found to be more important than the heparin and sham groups compared to the control group, while the sham group level difference was found to be more significant than the PTX and heparin groups. Our findings between control and sham groups were similar to those reported $[6,9,40]$. An increase is seen in NO concentration due to a harmful situation in the tissue [1]. NO is synthesized via L-arginine via NO synthase (NOS) enzyme [17]. Although studies on the role of NO in adhesion formation have been limited, it has been reported that intraperitoneal application of aminoguanidine [2], melatonin [3] and resveratrol [44] reduces the incidence of postnatal NO and the frequency and severity of peritoneal adhesions. In addition, heparin and NO may interact directly with each other, resulting in impaired NO function [49]. Pentoxifylline suppresses NO synthesis by inducing this compound at the level of mRNA [15] and may also directly inhibit NO formation by contributing to inhibition of apoptosis in this way [50]. This study shows that heparin or pentoxifylline significantly contributes to the reduction of $\mathrm{NO}$ accumulation due to intraperitoneal surgical procedures.

\section{CONCLUSION}

In conclusion, it was observed in this study that the use of heparin and pentoxifylline in the prevention of intraperitoneal adhesions significantly contributed to the reduction of intraperitoneal adhesions. Likewise, it was determined that this application had a significant effect on the reduction of the MDA level, which is an indicator of oxidative stress, after the surgical intervention. In conclusion, it is suggested that heparin and pentoxifylline should be used to prevent adhesions due to abdominal operations and to reduce oxidative damage.

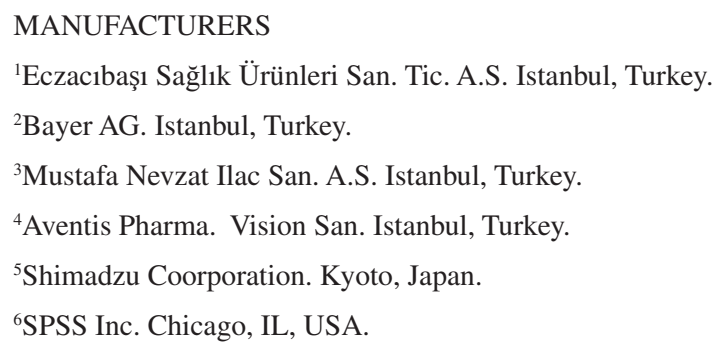

Ethical approval. The experimental protocols were approved by the local Animal Use Committees of Firat University (Elazig, Turkey).

Declaration of interest. The authors report no conflicts of interest. The authors alone are responsible for the content and writing of paper.

\section{REFERENCES}

1 Alpay Z., Saed G.M. \& Diamond M.P. 2006. Female infertility and free radicals: potential role in adhesions and endometriosis. Journal of the Society for Gynecologic Investigation. 13: 390-398.

2 Ara C., Bay Karabulut A., Kırımlıglu H., Yılmaz M., Kırımlıglu V. \& Yılmaz S. 2006. Protective effect of aminoguanidine against oxidative stress in an experimental peritoneal adhesion model in rats. Cell Biochemistry and Function. 24: 443-448. 
3 Ara C., Kırımlıglu H., Bay Karabulut A., Coban S., Hascalık S., Celik O., Yılmaz S. \& Kırımlıglu V. 2005. Protective effect of melatonin against oxidative stress on adhesion formation in the rat cecum and uterine horn model. Life Sciences. 77: 1341-1350.

4 Arıkan S., Adas G., Barut G., Toklu A.S., Kocakuşak A., Uzun H., Kemik Ö., Daduk Y., Aydın S. \& Purisa S. 2005. An evaluation of low molecular weight heparin anf hyperbaric oxygen treatment in the prevention of intra-abdominal adhesions and wound healing. The American Journal of Surgery. 189: 155-160.

5 Armagan A., Kutluhan S., Yilmaz M., Yilmaz N., Bülbü M., Vural H., Soyupek S. \& Naziroglu M. 2008. Topiramate and vitamin e modulate antioxidant enzyme activities, nitric oxide and lipid peroxidation levels in pentylenetetrazolinduced nephrotoxicity in rats. Basic \& Clinical Pharmacology \& Toxicology. 103(2): 166-170.

6 Arslan E., Talih T., Oz B., Halaclar B., Caglayan K. \& Sipahi M. 2014. Comparison of lovastatin and hyaluronic acid/carboxymethyl cellulose on experimental created peritoneal adhesion model in rats. International Journal of Surgery. 12: 120-124.

7 Arslan S., Zeytun H., Basuguy E., İbiloğlu İ., Uygun İ., Yılmaz A., Tan İ. \& Toprak G. 2017. Cordycepin prevents postoperative formation of intra-abdominal adhesion in a rat model. An experimental study. Ulus Travma Acil Cerrahi Dergisi. 23(4): 273-278.

8 Arung W., Meyrisse M. \& Detry O. 2011. Pathophysiology and prevention of postoperative peritoneal adhesions. The World Journal of Gastroenterology. 17: 4545-4553.

9 Askaria V.R., Rahimia V.B., Zamanib P., Fereydounic N., Devine P.R., Sahebkarb A.H. \& Rakhshandehe H. 2018. Evaluation of the effects of Iranian propolis on the severity of postoperational-induced peritoneal adhesion in rats. Biomedicine \& Pharmacotherapy. 99: 346-353.

10 Atilgan R., Kuloglu T., Ozkan Z.S., Kavak S.B., Kumbak B., Deveci D., Simsek M., Baspinar M. \& Sapmaz E. 2015. Evaluation of vitamin $\mathrm{C}$ and vitamin $\mathrm{E}$ for prevention of postoperative adhesion: A rat uterine horn model study. Journal of Obstetrics and Gynaecology Research. 4(3): 418-423.

11 Attar R., Yıldırım G., Kumbak B., Ficicioglu C., Demirbag S. \& Yesildaglar N. 2011. Efficacy of melatonin and hyaluronate/carboxymethycellulose membrane in preventing adhesion reformation following adhesiolysis in a rat uterine model. Journal of Obstetrics and Gynaecology Research. 37(2): 125-131.

12 Aziret M., Irkorucu O., Reyhan E., Erdem H., Das K., Ozkara S., Surmelioglu A., Sozen S., Bali I., Cetinkunar S. \& Deger K.C. 2014. The effects of vardenafil and pentoxifylline administration in an animal model of ischemic colitis. Clinics. 69(11): 763-769.

13 Bahadir L., Oncel M., Kement M. \& Sahip Y. 2007. Intra-abdominal use of taurolidine or heparin as alternative products to an antiadhesive barrier (Seprafilm ${ }^{\circledR}$ ) in adhesion prevention: an experimental study on mice. Diseases of the Colon \& Rectum. 50: 2209-2214.

14 Basbug M., Aygen E., Tayyar M., Kaya E., Narin F. \& Oktem O. 1998. Hyaluronic acid plus heparin for improved efficacy in prevention of adhesion formation in rat uterine horn model. European Journal of Obstetrics \& Gynecology and Reproductive Biology. 78: 109-112.

15 Beshay E., Croze F. \& Prud'Homme G.J. 2001. The phosphodiesterase inhibitors pentoxifylline and rolipram suppress macrophage activation and nitric oxide production in vitro and in vivo. Clinical Immunology. 98: 272-279.

16 Cortas N.K. \& Wakid N.W. 1990. Determination of inorganic nitrate in serum and urine by a kinetic cadmiumreduction method. Clinica Chimica Acta. 36: 1440-1443.

17 Derici M.K. \& Yilmaz E.D. 2017. The effects of nitric oxide on cancer development and metastasis. Turkish Bulletin of Hygiene and Experimental Biology. 74(2): 161-174.

18 Desia I.D. 1984. Vitamin E analysis methods for animal tissues. Methods in Enzymology. 105:138-147.

19 Drollette C.M. \& Badawy S.Z. 1992. Pathophysiology of pelvic adhesions. Modern trends in preventing infertility. The Journal of Reproductive Medicine. 37(2): 107-121.

20 Flora S., Izzotti A., Agostini F. \& Balansky R.M. 2001. Mechanism of Nacetylcysteine in the prevention of DNA damage and cancer,with special reference to smoking-related end-points. Carcinogenesis. 22(7): 999-1013.

21 Fukasawa M., Girgis W. \& diZerega G.S. 1991. Inhibition of postsurgical adhesions in a standardized rabbit model. II. Intraperitoneal treatment with heparin. International Journal of Fertility. 36(5): 296-301.

22 Galili Y., Ben Abraham R., Rabau M., Klausner J. \& Kluger Y. 1998. Reduction of surgeryinduced peritoneal adhesions by methylene blue. The American Journal of Surgery. 175: 30-32. 
23 Gomel V., Urman B. \& Gürgan T. 1996. Pathophysiology of adhesion formation and strategies for prevention. The Journal of Reproductive Medicine. 41: 35-41.

24 Goth L.A. 1991. A simple method for determination of serum catalase activity and revision of reference range. Clinica Chimica Acta. 196: 143-152.

25 Grant D., Long W.F., Mackintosh G. \& Williamson F.B. 1994. Heparins as essential antioxidants. Agents and Actions. 41: 214-215.

26 Hernandez Villaroel L.A., Cesin L. \& Fernandez H. 2016. Pentoxifylline effects on the formation of postoperative peritoneal adhesions in rats. Revista Científica Ciencia Médica. 19(1): 5-11.

27 Kamel R.M. 2010. Prevention of postoperative peritoneal adhesions. European Journal of Obstetrics \& Gynecology and Reproductive Biology. 150: 111-118.

28 Kaul N., Siveski Iliskovic N., Hill M., Slezak J. \& Singal P.K. 1993. Free radicals and the heart. Journal of Pharmacological and Toxicological Methods. 30: 55-67.

29 Kishi M., Tanaka H., Seiyama A., Takaoka M., Matsuoka T., Yoshioka T. \& Sugimoto H. 1998. Pentoxifylline attenuates reperfusion injury in skeletal muscle after partial ischemia. About American Journal Of Physiology-Heart And Circulatory Physiology. 274: 1435-1442.

30 Kinalski M., Sledziewski A., Telejko B., Zarzycki W. \& Kinalska I. 2000. Lipid peroxidation and scavenging enzyme activity in streptozotocin-induced diabetes. Acta Diabetologica. 37: 179-183.

31 Lai H.S., Chu S.Y., Chen Y., Wu C.H. \& Lin L.T. 1994. Effect of pentoxifylline on intraperitoneal adhesions after intestinal resection in rats. Journal of the Formosan Medical Association. 93: 911-915.

32 Lawrence R.A. \& Burk R.F. 1976. Glutathione peroxidase activity in selenium-deficient rat liver. Biochemical and Biophysical Research Communications. 71: 952-958.

33 Liakakos T., Thomakos N., Fine P.M., Dervenis C. \& Young R.L. 2001. Peritoneal adhesions: etiology, pathophysiology and clinical significance. Recent advances in prevention and management. Digestive. Surgery. 18: 260-273.

34 Lowry O.H., Rosebrough N.J., Farr A.L. \& Randall R.J. 1951. Protein measurement with the Folin-Phenol reagent. Journal of Biological Chemistry. 193: 265-275.

35 Nair S.K., Bhat I.K. \& Aurora A.R. 1974. Role of proteolytic enzymes in the prevention of postoperative intraabdominal adhesions. The Archives of Surgery. 108: 849-853.

36 Okumura A.S., Rodrigues L.E. \& Martinelli R. 2009. Pentoxifylline in ischemia-induced acute kidney injury in rats. Renal Failure. 31: 829-832.

37 Perry J.F., Smith A.G. \& Yonethiro E.G. 1955. Intestinal obstruction caused by adhesion. Annals of Surgery. 142: 810-816.

38 Placer Z.A., Cushman L. \& Johnson B.C. 1966. Estimation of products of lipid peroxidation (malonyl dialdehyde) in biological fluids. Analytical Biochemistry. 16: 359-364.

39 Pratt S. \& Ioannides C. 1985. Mechanism of the protective action of nacetylcysteine and methionine against paracetamol toxicity in the hamster. Archives Toxicology. 57: 173-177.

40 Rahimia V.B., Shiraziniaa R., Fereydounib N., Zamanic P., Darroudib S., Sahebkard A.H. \& Askaria V.R. 2017. Comparison of honey and dextrose solution on post-operative peritoneal adhesion in rat model. Biomedicine \& Pharmacotherapy. 92: 849-855.

41 Ross M.A., Long W.F. \& Williamson F.B. 1992. Inhibition by heparin of Fe(II)-catalysed free-radical peroxidation of linolenic acid. Biochemical Journal. 286: 717-720.

42 Sedlak J. \& Lindsay R.H.C. 1968. Estimation of total, protein bound and non-protein sulfhydryl groups in tissue with Ellmann's reagent. Analytical Biochemistry. 25: 192-205.

43 Singal P.K., Beamish R.E. \& Dhalla N.S. 1983. Potential oxidative pathways of catecholamines in the formation of lipid peroxides and genesis of heart disease. Advances in Experimental Medicine and Biology. 161: 391-401.

44 Sögütlü G., Bay Karabulut A., Ara C., Cinpolat O., Issk B., Piskin T. \& Celik O. 2007. The effect of resveratrol on surgery-induced peritoneal adhesions in an experimental model. Cell Biochemistry and Function. 25: 217-220.

45 Steinleitner A., Lambert H., Kazensky C., Danks P. \& Roy S. 1990. Pentoxifylline, a methylxanthine derivative, prevents postsurgical adhesion reformation in rabbits. Obstetrics \& Gynecology. 75: 926-928.

46 Sun Y., Oberley L.W. \& Li Y. 1988. A simple method for clinical assay of superoxide dismutase. Clinical Chemistry. 34: 497-500. 
47 Suzuki J. \& Katoh N.A. 1990. Simple and cheap methods for measuring serum vitamin A in cattle using only a spectrophotometer. The Japanese Journal of Veterinary Science. 52: 1282-1284.

48 Tarhan O.M., Barut I., Sütcü R., Akdeniz Y. \& Aktürk O. 2006. Pentoxifylline, a methly xanthine derivative, reduces peritoneal adhesions and increases peritoneal fibrinolysis in rats. The Tohoku Journal of Experimental Medicine. 209: 249-255.

49 Upchurch G.R., Goodman D.G., Willoughby S.R., Zhang Y.Y., Welch G.N., Freedman J.E., Ye S., Costello C.E. \& Loscalzo J. 2001. Heparin reacts with and inactivates nitric oxide. Journal of Cardiovascular Pharmacology and Therapeutics. 6: 163-173.

50 Usta Y., Ismailoglu U.B., Bakkaloglu A., Orhan D., Besbas N., Sahin-Erdemli I. \& Ozen S. 2004. Effects of pentoxifylline in Adriamycin-induced renal disease in rats. Pediatric Nephrology. 19: 840-843.

51 Verhagen H., Buijsse B., Jansen E. \& Bueno-de-Mesquita B. 2006. The state of antioxidant affairs. Nutrition Today. 41: 244-250.

52 Yetkin G., Uludağ M., Citgez B., Karakoc S., Polat N. \& Kabukcuoglu T. 2009. Prevention of peritoneal adhesions by intraperitoneal administration of vitamin E and human amniotic membrane. International Journal Surgery. 7: 561565.

53 Yildiz H., Durmuş A.S., Şim ek H. \& Yaman I. 2011. The comparison of methylene blue and vitamin E in prevention of abdominal postoperative adhesion formation in rat uterine horn models. Biochemical and histopathologic evaluation. Acta Cirúrgica Brasileira. 26: 51-57.

54 Yousef M.I., Abdallah G.A. \& Kamel K.I. 2003. Effect of ascorbic acid and vitamin E supplementation on semen quality and biochemical parameters of male rabbits. Animal Reproduction Science. 76(1-2): 99-111.

55 Yovich J.M., Ediringhe W.R., Cummins J.M. \& Yovich J.L. 1990. Influence of pentoxifylline in pelvic peritoneal macrophages. Fertility and Sterility. 46: 715-722. 